\title{
A MUDANÇA NO DIREITO MODERNO NO BRASIL A PARTIR DO DEBATE DAS RELAÇÕES MORAIS DO "MUNDO DA VIDA"
}

\section{THE CHANGES IN MODERN LAWS IN BRAZIL STARTING FROM THE DEBATE IN THE "WORLD LIFE"}

Leonardo Tajes Ferreira ${ }^{1}$

\section{RESUMO}

Tendo como base a Teoria Crítica de Jürgen Habermas e a visão de Michel Foucault sobre a dominação de caráter microssocial, este trabalho visa debater o papel do Direito na democracia brasileira e seu impacto como garantidor do respeito à pluralidade de vivências, uma vez que a moral ética pautada no diálogo não vem se mostrando um modo efetivo de se garantir a harmonia na convivência social.

Palavras-chaves: Moral. Homossexualidade. Direito.

\section{ABSTRACT}

Based on Jürgen Habermas's Critical Theory and Michel Foucault's view on the domination of a microsocial character, this paper aims to debate the role of Law in Brazilian democracy and its impact as a guarantee of respect for the plurality of experiences, once an ethic Morality based on dialogue has not shown an effective way of guaranteeing harmony in social life.

Keywords: Moral. Homosexuality. Law.

\section{INTRODUÇÃO}

Em 13 de junho de 2019 o Supremo Tribunal Federal (STF) determinou a criminalização da homofobia em território nacional. A ação sucede duas importantes conquistas para a comunidade LGBT+: a liberação, em 2010, pelo Superior Tribunal de Justiça (STJ), de casais homoafetivos terem o direito de abrir o processo de adoção, e no ano seguinte haver o reconhecimento, por parte do STF, do casamento de pessoas do mesmo sexo como "entidade

\footnotetext{
${ }^{1}$ Mestrando em Sociologia - UFPEL, Jornalista. e - mail: tajjes2@ hotmail.com
} 
familiar". Mesmo com os recentes avanços nos direitos voltados à comunidade LGBT+ os casos de violência ainda são parte do cotidiano. Violência psicológica (ameaças e humilhações), discriminação (por gênero ou orientação sexual) e violência física (homicídios e lesões corporais) estão entre as principais denúncias do "Disque 100", instrumento desenvolvido pelo Ministério dos Direitos Humanos (MDH), que registrou em 2018 um número de denúncias maior que no ao anterior.

Segundo levantamento realizado em 2017 pelo jornal "O Globo", a cada 19 horas um LGBT é assassinado ou se suicida vítima da "LGBTfobia". Dados estatísticos coletados pela associação "Grupo Gay da Bahia" (GGB), no mesmo ano, mostraram que houve um aumento de 30\% no número de homicídios de LGBTs no Brasil. O número de crimes com armas de fogo em 2017 era de 30,8\%, e com arma branca (25,2\%); destes, 56\% ocorreram em via pública, e $37 \%$ dentro de residências, muitos na casa da própria vítima. Das 445 mortes registradas 194 eram gays (43,6\%), 191 transsexuais (42,9\%), 43 lésbicas $(9,7 \%), 5$ bissexuais $(1,1 \%)$ e 12 heterossexuais $(2,7 \%)$. Conforme dados publicados em março de 2019 pela ILGA (Associação Internacional de Lésbicas, Gays, Bissexuais, Transsexuais e Intersexuais), maior organização mundial em defesa dos direitos LGBTI+, há no mundo 70 países que ainda tratam a homossexualidade como crime, 44 deles a criminalização se dá de modo geral. Em seis localidades é prevista a pena de morte para os casos.

Como consequência da mobilização de ativistas, simpatizantes da causa e da comunidade LGBT+, o Poder Legislativo no Brasil tem se mostrado aberto a incorporar as demandas dos LGBT+ dentro da jurisdição. Este trabalho visa, a partir da perspectiva teórica de Jürgen Habermas e Michel Foucault, analisar de que modo ocorre a incorporação das demandas particulares composta pela comunidade LGBT+ dentro do contexto político e social brasileiro do século XXI.

\section{O PODER E A DOMINAÇÃO EM MICHEL FOUCAULT}

O sociólogo, jurista, e economista alemão MAX WEBER (1987) desenvolveu seu método compreensivo na formulação de Tipos Ideais para analisar a sociedade e descobrir as 


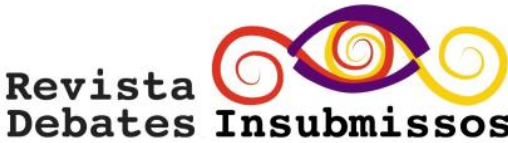

causalidades dos fenômenos. Os Tipos Ideais são abstrações da realidade que criam categorias, quadros mentais, que visem conexões de sentidos das ações sociais dentro de determinados contextos.

Ao contrário de Émile Durkheim que buscava as generalizações, Weber está à procura das particularidades; deste modo, o homem como indivíduo e dotado de significados e especificidades passam a ser objeto de estudo da sociologia. A interpretação da ação social do indivíduo é fruto do deslocamento da ênfase nas totalidades supra individuais para o indivíduo. Os tipos ideais de ação social classificados por Weber são: a afetiva, ações movidas por impulsos, como orgulho, vingança ou paixões; a tradicional, o agir guiado por costumes de uma sociedade; a ação racional com relações a fins trata da elaboração de meios ou procedimentos com finalidades racionais e objetivas; a ação racional movida por valores tem ligação com valores morais e éticos, como também crenças. O sentido destas ações valorativas pode acarretar no "paradoxo das consequências", quando a intenção primeira não é interpretada em conformidade pelos receptores. Segundo Weber as ações sociais mais afastadas da racionalidade são: a tradicional e a afetiva. Na obra de WEBER (1981) as ações sociais ocorrem orientadas por probabilidades típicas, levando-se em consideração o outro, caracterizando assim uma microsociologia fenomenológica. Weber também conceitua os tipos ideais de dominação, sendo elas: a dominação tradicional, pautada na autoridade sólida, no respeito e na fidelidade; a carismática, baseada na devoção, fatores afetivos e qualidades excepcionais do líder; a dominação legal se dá pelo aparato das legislações ou estatutos vigentes, onde a impessoalidade e a hierarquia são a base das relações.

Até a década de 1960 houve, dentro da sociologia, forte influência do pensamento weberiano para a compreensão das relações de dominação. O poder nesta perspectiva estruturalista é visto como um ponto linear centralizado pelo Estado; esse que é detentor do monopólio do exercício da violência e dominação legítimas. O aumento da racionalização da vida fez com que Weber distinguisse a história em duas configurações de vida social: a comunidade e a sociedade. Na primeira há menos pessoas e as relações são pautadas no afeto e na tradição. Na sociedade, onde a racionalidade guia a maioria das ações, se tem maior número 


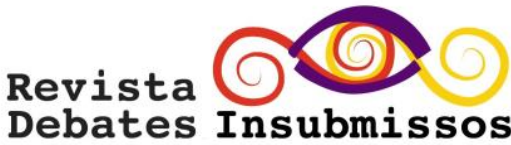

de pessoas nas cidades, e, portanto, maior ocorrência de conflitos sociais, o que reforça a demanda do poder do Estado como regulador das ações microssociais.

O filósofo francês Michel Foucault (2009) vê a dominação de uma outra forma, que se aproxima de um sistema de rede. $\mathrm{O}$ autor buscou em suas obras compreender de que forma o poder funciona, e de que modo a dominação se manifesta. Sendo assim, a partir do conceito de "microfísica do poder", para o autor, o poder está amparado nas relações estabelecidas entre os indivíduos e não centrada nas ações reguladoras do Estado. Os aspectos mais marcantes das mudanças ocorridas na sociedade, na transição do período das "sociedades tradicionais" para as "sociedades contemporâneas", ocorrem no modo como as punições físicas se redimensionam para um disciplinamento dos indivíduos. Em "Vigiar e Punir" (2008) Foucault traz o suplício como um "poder moderno"; essa violenta prática do Estado era uma punição corpórea, que vigorou entre os séculos XVI e XVIII. Para Foucault (2008, p. 62) “Um suplício bem-sucedido justifica a justiça, na medida em que publica a verdade do crime no próprio corpo do supliciado". A partir do século XVIII a "alma" passa a ser punida e regulada através de instituições, como a Escola, a Igreja, o Exército e os Asilos. Segundo Foucault (2008, p. 33) “Uma 'alma' o habita e o leva à existência, que é ela mesma uma peça no domínio exercido pelo poder sobre o corpo". A noção de "panóptico" em Foucault faz uma analogia entre o sistema de vigilância prisional e a disciplina imposta pelo olhar hierárquico das instituições de disciplinamento dos corpos.

O sistema panóptico prisional, criado em 1785, pelo filósofo iluminista britânico Jeremy Benthan, consistia de uma penitenciária de estrutura circular, onde no centro do edifício havia uma guarita de vigilância onde os presos seriam vigiados sem a possibilidade de enxergar quem os observa. Segundo Foucault (2008, p. 224), o panóptico “induzir no detento um estado consciente e permanente de visibilidade que assegura o funcionamento automático do poder. Fazer com que a vigilância seja permanente em seus efeitos". Dentro da perspectiva de Foucault, a disciplina na sociedade ocorre pelo "olhar hierárquico", pela "sanção normalizadora" e o "exame", a constante avaliação do indivíduo. Deste modo, as relações de poder estão mais pautadas nas normas impostas socialmente por padrões sociais do que leis. 


\section{Revista \\ Debates Insubmissos}

O discurso, para Foucault, enquanto rede de enunciados dotados de significantes e significados, é uma forma de impor a verdade aos que ouvem. Dentro do que o autor chama de sistemas excludentes das práticas discursivas ocorre a eliminação dos que não se adequam ao padrão aceito pela coletividade social. Segundo Foucault há três formas de sistemas de exclusão: a "Interdição", que é o silenciamento de uma parcela da população pela desconsideração de seus repertórios pelo resto da sociedade; a "Separação" , é a rejeição às ideias por elas não se adequarem ao que já está imposto e aceito pela coletividade; a "Oposição" lida com caráter de respeito e justiça atrelado a um discurso, sendo a aceitação de seu repertório relacionado a parâmetros dicotômicos como "verdade" e "mentira", o "correto" e o "errado". Foucault define o discurso como "Um conjunto de regras anônimas, históricas sempre determinadas no tempo espaço, que definiram em uma dada época (...) as condições de exercício da função enunciativa" (FOUCAULT, 2009, p. 43).

A noção de dominação simbólica abordada na obra de Foucault nos ajuda a compreender como as formas de dominação nas relações microssociais ocorrem dentro das interações entre heterossexuais e homossexuais. A não aceitação da homossexualidade, a infelicidade matrimonial e a vida dentro do "armário" (gíria popular para homens e mulheres não assumidos homossexuais) decorre das pressões sociais e da imposição normativa que por vezes se sobrepõe às legislações vigentes. Ainda que não haja uma sanção normativa do Estado contra a comunidade LGBT+ no território brasileiro, o confrontamento ao repertório discursivo desta comunidade é frequente, sendo a violência física e simbólica uma constante.

\section{O DIREITO E A MORAL}

O filósofo alemão Jürgen Habermas, representante da segunda geração da Escola de Frankfurt, abordou em suas obras questões referentes à racionalidade e à emancipação humana. Habermas se opôs aos teóricos do positivismo científico de base iluminista, e aos sistemas fechados de interpretação social. Nascido em 1929, Habermas presenciou a Segunda Guerra Mundial (1939 - 1945) e experenciou os efeitos desta na sociedade europeia. Deste modo, esta vivência se refletiu em sua obra, que objetivava compreender a situação histórico-cultural da 


\section{Revista \\ Debates Insubmissos}

sociedade a fim de converter sua teoria filosófica em uma forma de transformar uma realidade ainda marcadas por lutas e contradições sociais.

Habermas é um crítico da teoria da "razão instrumental" conceituada por Max Weber, e posteriormente trabalhada pela primeira geração da Escola de Frankfurt, composta por Theodor Adorno e Max Horkheimer. A razão instrumental consiste na redução das relações sociais ao caráter objetivo e utilitarista, onde o cientificismo anula as percepções que não podem ser quantificadas e classificadas de modo restrito, como fatores éticos e morais. Tendo como base a teoria de Kant (2001), de imperativos categóricos ligados ao dever moral, Habermas acredita que a razão instrumental gera sujeitos reificados, definindo duas características principais: os heterônomos, que se limitam a obedecer às normas, e os solitários, que se isolam do contato interpessoal. A razão instrumental também é caracterizada por Habermas pela falta de significado de conceitos como "liberdade", "igualdade" e "solidariedade". Em contraponto, o sujeito autônomo e solidário, conceituado por Habermas, deve ser movido pelo interesse técnico (aplicação da técnica para benefício humano), pelo interesse prático (centrado nas relações), e pelo interesse emancipatório (ligado à liberdade do ser humano). Segundo Habermas "Normas morais regulam relações interpessoais e conflitos entre pessoas naturais, que se reconhecem reciprocamente como membros de uma comunidade concreta" (2003, p. 147). O interesse emancipatório, guiado pelo interesse técnico-científico, interesse prático, e pela Sociologia e História, deve guiar a os indivíduos para o caminho da liberdade.

Habermas propôs a "Teoria da Ação Comunicativa", embasando-se no diálogo e na comunicação como formas de se atingir um consenso social pautado pela ética. Defensor de uma democracia deliberativa, Habermas acredita na possibilidade de um sistema político baseado nas escolhas éticas, que visem a harmonia. A democracia para Habermas é a autoorganização da sociedade por cidadãos unidos comunicativamente. A política em Habermas é a extensão do uso público da palavra, e a abstenção, a não manifestação. Sendo assim, a constituição da sociedade, segundo Habermas, deve prever certas "pretensões", como: a “inteligibilidade", de comunicação de fácil compreensão; "verdade", ligado à veracidade dos 


\section{Revista \\ Debates Insubmissos}

fatos explicitados; "sinceridade", mostrar o que de fato se acredita; e "correção normativa", onde se deve ser correto conforme os contextos, normas e valores vigentes.

Habermas separa em duas esferas a sociedade: "Sistema" e "Mundo da Vida". O Sistema consiste na ação estratégica, ligado ao modo de pensar atrelado aos meios de produção capitalistas. Por outro lado, o Mundo da Vida está pautado na comunicação, em uma ação comunicativa onde há a harmonia de interesses coletivos, um consenso. De acordo com Habermas, como consequência do desenvolvimento das sociedades capitalistas houve uma interferência direta do Mundo da Vida pelo Sistema; ou seja, as ações estratégicas de sucesso individual, de razão instrumental, presente no sistema, dominaram as ações de afetividade humana. Segundo Habermas, através dos regimes democráticos constituídos da modernidade, é possível fomentar o diálogo e a participação. Deste modo, o sistema passaria a operar para o mundo da vida, se configurando uma relação transversal de igualitárias oportunidades de fala. Para Habermas (2002, p. 55) "O respeito reciprocamente equânime por cada um, exigido pelo universalismo sensível a diversificações, é do tipo de uma inclusão não-niveladora e nãoapreensória do outro em sua alteridade".

A linguagem visa alcançar o consenso a partir do compartilhamento das percepções de mundo e para dirigir ações dentro de uma comunidade de significados (condições de possibilidades). $\mathrm{O}$ acordo, ou o consenso, ocorre quando todos os participantes do diálogo têm o mesmo direito de falar; sendo esta relação de solidariedade possível pelos fatores morais que guiam as ações. Uma vez que as estruturas de ação estão orientadas pela reciprocidade, a moralidade, intrinsicamente atrelada ao discurso e à ação comunicativa, pode ser considerada, na perspectiva de Habermas, uma condição de possibilidade para a vida social. Para Habermas (1989, p. 43) “Ao tomarem parte em ações comunicativas, aceitam por princípio o mesmo status daqueles cujos proferimentos querem compreender". A ética discursiva, em Habermas, está baseada na compreensão do discurso a partir da argumentação utilizada a respeito de normas morais, posteriormente estabelecer uma averiguação do que deve ser considerado "moralmente corretas", e, consequentemente, estudar as condições em que os diálogos estão inseridos. Após a discussão de problemas ligados à moralidade de determinadas ações ocorre a produção de 


\section{Revista \\ Debates Insubmissos}

consenso, que só é possível pelo debate entre interlocutores válidos (com condições de simetria), e através de argumentações plausíveis, pautadas pela razão. Em suma, a moral é chegar a acordos mediante racionalidade comunicativa.

Para Habermas qualquer pessoa pode participar do discurso, podendo problematizar e incluir qualquer afirmação, expressar opiniões, desejos e necessidades sem a coação ou intervenção de qualquer natureza. Para o diálogo não se caracterizar como imoral Habermas estabelece postulados, como: a "universalização", compartilhar as mesmas normas; "ético discursivo", onde não há dogmas ou relativismos, mas sim a imparcialidade, a solidariedade e a universalidade regem as ações.

A ciência para Habermas deveria ser experimental, sem dogmas, intersubjetiva e autocrítica. Segundo o autor, as afirmações mais bem fundamentadas podem ser falsas, devendo-se atentar para a qualidade do procedimento, o único que garante a melhor escolha dos argumentos. A racionalidade moral, submetida a certos procedimentos científicos, pode ser estudada através de suas normas vigentes visando identificar as simetrias das perspectivas dos interagentes e os conteúdos imersos. A moral deve ter a capacidade de criticar condutas e normas vigentes e dar razões que transcendam sua comunidade, incluindo interesses e pretensões. Os discursos argumentativos não excluem membros da comunidade; nada que seja capaz de usar a linguagem, o pensamento e a ação. Deste modo, argumentar é o ato de descentra-se da própria perspectiva particular. A partir do particularismo de uma reflexividade individual é possível chegar às concepções intersubjetivas compartilhadas. A partir disto que se é possível pensar no conceito que Habermas chama de "universalismo das diferenças". Fruto do diálogo ético condicionado pela igualdade, imparcialidade e universalidade, o "universalismo das diferenças" é a única ética universal embasada no consenso. Conforme a teoria de Habermas "A força social e integradora da solidariedade, que não pode ser extraída apenas de fontes do agir comunicativo, deve desenvolver-se através de um amplo leque de esferas públicas autônomas" (2003, p. 22).

Este universalismo, no entanto, não significa que as pessoas compartilham das mesmas concepções de vida; o que ocorre é que há o compartilhamento de procedimento racionais de 


\section{Revista \\ Debates Insubmissos}

argumentação. As várias formas de comunidades étnicas, grupos linguísticos e fragmentações da sociedade englobam o Patriotismo Constitucional, uma cultura política comum que abarca uma cultura constitucional onde as diferenças não são relevantes, mas sim a aglutinação das distintas sensibilidades pelo acordo normativo racional, intrínseco à democracia. A razão comunicativa proposta por Habermas "encontra os seus critérios no procedimento argumentativo da liquidação direta ou indireta de exigências de verdade proposicional, justeza normativa, veracidade subjetiva e coerência estética" (1990, p. 291).

Dentro da perspectiva de Habermas, a moral e o direito nas sociedades modernas têm uma relação complementar e uma relação diferenciada. A perda da eticidade que perpassa todos os âmbitos sociais, a partir do processo de transição das sociedades tradicionais para as modernas, há uma mudança no modo de "fundamentação", um nível de fundamentação pósmetafísico marcado pelas interações cada vez mais complexas e plurais. Deste modo, a moral e o Direito operam lado a lado a partir de uma razão comunicativa, uma consequência da crescente reflexividade humana. Em Habermas, a ordem jurídica compensa, de modo limitado, dentro do mundo dos fenômenos (sistema), as deficiências, ou carências, de uma moral racional autônoma que resultou da decomposição da eticidade tradicional. A moral desempenha um papel importante para a resolução dos problemas na coordenação da ação no mundo da vida, porém, não o suficiente em determinados casos. Assim, esta operação de "saber" carece de efetividade e critérios absolutos, dada a pluralidade das esferas culturais de valor da modernidade e meios de legitimidade da moral. O Direito positivo moderno, em Habermas, tem a peculiaridade de ser um saber cultural e um sistema de ação que se complementa à moral ética. A efetividade da moral se dá mediante a coerção do aparato jurídico (sistema de ação), que é capaz de ser interpretado tanto como textos repletos de proposições e interpretações normativas, como também um sistema de ação à medida que institucionaliza as normas em um sistema jurídico de eficácia imediata. Nesta perspectiva, o direito reduz o indivíduo a uma pessoa de direito, retirando do indivíduo o "peso moral" de julgar e agir moralmente conforme os parâmetros das exigências cognitivas, motivacionais e organizacionais. 


\section{METODOLOGIA}

Este ensaio visa estabelecer um levantamento bibliográfico de temáticas centradas na dominação, poder e questões morais e jurídicas dentro da perspectiva teórica de Jürgen Habermas e Michel Foucault.

Ao analisarmos o contexto brasileiro de luta por direitos para os homossexuais e as diferentes vertentes dentro da comunidade LGBT+, constata-se que houve avanços na esfera jurídica. Neste sentido, acreditamos que a teoria de Habermas, presente na obra "Teoria do Agir Comunicativo", nos auxilia a explicar de que modo se estabelece esta mudança no setor jurídico, onde há uma interferência do mundo da vida (de caráter moral) dentro do sistema racional do direito.

A obra "Vigiar e Punir" de Michel Foucault, contribui com este trabalho a partir do levantamento histórico que o autor faz para caracterizar a mudança comportamental entre a Idade Média e a Idade Contemporânea. Segundo o autor, estes momentos históricos foram marcados pela passagem de um poder repressivo do Estado para um poder restitutivo, de caráter disciplinador. O impacto que esta mudança exerceu na mentalidade humana pode ser observado ainda na atualidade, onde os gostos pessoais

\section{ANÁLISE}

A Teoria Crítica de Jürgen Habermas nos auxilia a compreender de que modo as questões morais estabelecidas no mundo da vida são transferidas para a esfera jurídica das democracias deliberativas. Uma vez que a moral e o diálogo não se mostram suficientes para a convivência harmônica de sujeitos cada vez mais plurais e complexos cabe ao direito servir complemento nestas relações.

$\mathrm{Na}$ realidade brasileira, onde o machismo e a homofobia ainda são constantes, a garantia de direitos jurídicos torna-se um amparo de proteção legitima, tanto das mulheres como dos homossexuais, respectivamente. Sendo assim, o cenário de patologia social (de esgotamento da base comunicativa) no Brasil requer uma maior presença do Estado (Sistema) 
sobre a moral (Mundo da Vida); o que não impede que o contrário também ocorra, ou seja, que as relações no Mundo da Vida interfiram no Sistema do país, como ocorreu com a proposição e promulgação de leis que preveem juridicamente o direito à união estável de casais ou adoção de crianças por parceiros, e parceiras, homoafetivos.

\section{CONCLUSÕES}

Podemos constatar que o contexto de repressão física e simbólica de caráter microssocial, conforme os moldes conceituados por FOUCAULT (2009), vem provocado mudanças estruturais do Direito brasileiro. Uma vez que o diálogo entre as partes não vem se mostrado suficientemente efetivo para a coesão social, a influência do Estado se mostra um poder legitimador das formas de vivências plurais. No entanto, tendo como parâmetro o histórico de violência contra a comunidade LGBT+, o reconhecimento no âmbito jurídico não se mostrou um meio de frear a violência; podendo ser necessário o constante reforço discursivo através de movimentos sociais ou ciclos de confrontos, conforme conceitua SIDNEY TARROW (2009), para que estas identidades sejam, de fato, reconhecidas e legitimadas socialmente.

\section{REFERÊNCIAS}

FOUCAULT, Michel. Vigiar e punir. Petrópolis: Vozes, 2008.

FOUCAULT, Michel. A Arqueologia do Saber. Rio de Janeiro: Forense Universitária, 2009. HABERMAS, J. Consciência moral e agir comunicativo. São Paulo: Brasiliense, 1989. HABERMAS, J. Teoria do Agir Comunicativo: racionalidade da ação e racionalização social. v. I. Tradução Paulo Astor Soethe. São Paulo: WMF Martins Fontes, 2012.

HABERMAS, J. Direito e Democracia: entre facticidade e validade. 2 v. Trad. Flávio Beno Siebeneichler. $2^{\mathrm{a}}$ ed. Rio de Janeiro: Tempo Brasileiro, 2003. 
HABERMAS, J. A inclusão do outro: estudos de teoria política. Trad. George Sperber e Paulo Astor Soethe. São Paulo: Edições Loyola, 2002.

HABERMAS, Jürgen. Direito e democracia: entre facticidade e validade. v. I. Trad. Flávio Beno Siebeneichler. Rio de Janeiro: Tempo Brasileiro, 1997.

HABERMAS, J. O discurso filosófico da modernidade. Lisboa: Dom Quixote, 1990.

KANT, Immanuel. Crítica da Razão Pura. $5^{\text {a }}$ Edição. Trad.: Manuela Pinto e Alexandre Morujão. Lisboa: Fundação Calouste Gulbenkian, 2001.

SOUTO, Luiza. Assassinatos de LGBT crescem $30 \%$ entre 2016 e 2017, segundo relatório. Disponível em: https://oglobo.globo.com/sociedade/assassinatos-de-lgbt-crescem30-entre-2016-2017-segundo-relatorio-22295785. Acesso em: 14 set. 2019.

SOUSA, Viviane; ARCOVERDE, Léo. Brasil registra uma morte por homofobia a cada 23 horas, aponta entidade LGBT. Disponível em: https://g1.globo.com/sp/saopaulo/noticia/2019/05/17/brasil-registra-uma-morte-por-homofobia-a-cada-23-horas-apontaentidade-lgbt.ghtml. Acesso em: 14 set. 2019.

TARROW, Sidney. O poder em movimento: movimentos sociais e confronto político: tradução de Ana Maria Sallum - Petrópolis, RJ: Vozes, 2009.

WEBER, Max. A Ética Protestante e o Espírito do Capitalismo. 5 ed. São Paulo: Pioneira, 1987.

WEBER, Max. Ensaios de Sociologia. Ed. Guanabara: Rio de Janeiro, 1981.

Submetido em: 23/10/2019

Aprovado em: 05/03/2020 